\title{
A educação em direitos humanos como política pública no Brasil
}

\author{
- Human rights education as public policy in Brazil \\ - La educación en derechos humanos como política \\ pública en brasil
}

Erasto Fortes Mendonça'

Resumo: O objeto do presente artigo é a Educação em Direitos Humanos como política pública no Brasil. Partindo de uma aproximação inicial e conceitual sobre o tema das políticas públicas, são focalizados a educação, os direitos humanos e a própria educação em direitos humanos como políticas públicas. Para tanto, procura-se responder a questão preliminar sobre como surgem as políticas públicas. A partir de processos participativos, a sociedade estabelece quais os temas de interesse geral que devam ser considerados públicos para que se constituam ações do Estado, tornando-se políticas públicas e tendo como finalidade precípua a fruição de direitos. Ao reconhecer que esse é um campo de disputas, são apontadas eventuais dificuldades para que as políticas públicas estejam, de fato, a serviço de resoluções de problemas públicos, sendo o ambiente democrático o mais eficiente para que a resolução de conflitos seja alcançada. A partir dessa abordagem, são descritos os processos de assunção da prática social da educação e dos direitos humanos como política pública no Brasil, para evidenciar que esses movimentos possibilitaram que a educação em direitos humanos fosse igualmente tomada pelo Estado como objeto de política pública. São descritas as ações que promoveram a criação de instâncias governamentais e de marcos regulatórios sobre a educação em

1 Pós-doutor pela UFG, doutor em Educação pela Unicamp e mestre em Educação pela UnB. Professor da UnB. Foi Coordenador Geral de Educação em Direitos Humanos e Diretor de Promoção dos Direitos Humanos da Secretaria Especial de Direitos Humanos da Presidência da República (2007-2011). E-mail: erastofm@gmail.com 
direitos humanos e que permitem que o Brasil seja reconhecido como Estado nacional que detém uma estrutura orgânica e normativa consoante às orientações internacionais desse campo. No entanto, a situação política e social vivida pelo país a partir do afastamento da presidente eleita ocorrido em 2016, desenha uma conjuntura de profundos retrocessos em relação às conquistas de direitos no campo da educação e dos direitos humanos. É nesse cenário que a educação em direitos humanos e a reativação da Rede Brasileira de Educação em Direitos humanos são apontadas como importantes mecanismos de resistência tendo em vista a radicalização e o fortalecimento da democracia e do estado democrático de direito.

Palavras-chave: Políticas públicas. Educação. Direitos humanos. Educação em direitos humanos.

Resumen: El objeto de investigación de este artículo es la Educación en Derechos Humanos como política pública en Brasil. Partiendo de una aproximación inicial y conceptual al tema de las políticas públicas, destaca la educación, los derechos humanos y los derechos humanos en la educación como políticas públicas. Para este fin, intenta dar respuesta a la pregunta preliminar sobre cómo surgen las políticas públicas. A partir de procesos participativos, la sociedad establece temas de interés general que deben ser considerados públicos para constituir acciones de Estado, convertirse en políticas públicas y tener como finalidad primordial el cumplimiento de los derechos. Al reconocer que este es un campo de disputas, se señalan posibles dificultades para que las políticas públicas estén, de hecho, al servicio de la solución de problemas públicos, siendo el entorno democrático el más eficiente para lograr la resolución de conflictos. Desde este enfoque, se describen los procesos de asumir la práctica social de la educación y los derechos humanos como política pública en Brasil, con el fin de mostrar que estos movimientos hicieron posible que la educación en derechos humanos fuera tomada como objeto de política pública por parte de lo Estado. Describe las acciones que promovieron la creación de órganos de gobierno y marcos regulatorios en educación en derechos humanos, y que permiten que Brasil sea reconocido como un Estado nación que tiene una estructura orgánica y normativa acorde a los lineamientos internacionales de este campo. Sin embargo, la situación política y social que vive el país desde el juicio político contra la presidenta electa en 2016, dibuja un contexto de profundos retrocesos en relación a la consecución de los derechos en el ámbito de la educación y los derechos humanos. En este escenario, la educación en derechos humanos y la reactivación de la Red Brasileña de Educación en Derechos Humanos se identifican como importan- 
tes mecanismos de resistencia, debido a la radicalización y fortalecimiento de la democracia y el estado de derecho democrático.

Palabras clave: Políticas públicas. Educación. Derechos humanos. Educación en derechos humanos.

\begin{abstract}
The research object of this article is Education in Human Rights as a public policy in Brazil. Starting from an initial and conceptual approach to the theme of public policies, it highlights education, human rights, and human rights in education as public policies. To this end, it attempts to answer the preliminary question about how public policies emerge. Based on participatory processes, society establishes themes of general interest that must be considered public to constitute State actions, become public policies, and have as a primary purpose the fulfillment of rights. When recognizing that this is a field of disputes, possible difficulties are pointed out so that public policies are, in fact, at the service of solving public problems, with the democratic environment being the most efficient to achieve conflict resolution. From this approach, the processes of assuming the social practice of education and human rights as public policy in Brazil are described, in order to show that these movements made it possible for education in human rights to be taken as an object of public policy by the State. It describes the actions that promoted the creation of government bodies and regulatory frameworks on human rights education, and that allow Brazil to be recognized as a nation state that has an organic and normative structure according to the international guidelines of this field. However, the political and social situation experienced by the country since the impeachment of the elected president in 2016, draws a context of profound setbacks in relation to the achievement of rights in the field of education and human rights. In this scenario, human rights education and the reactivation of the Brazilian Human Rights Education Network are identified as important mechanisms of resistance, because of the radicalization and strengthening of democracy and the democratic rule of law.
\end{abstract}

Keywords: Public policies. Education. Human rights. Human rights education.

A abordagem da Educação em Direitos Humanos (EDH) como política pública sugere, para melhor compreensão da temática, uma aproximação inicial e conceitual sobre o tema mais geral das políticas públicas. Isso permite focalizar a Educação, os Direitos Humanos e, por fim, a EDH como políticas públicas 
no Brasil e assinalar a importância da EDH como instrumento para a materialização dos direitos e o fortalecimento da democracia.

Cabe, inicialmente, responder a uma pergunta fundamental. Como surgem as políticas públicas? O ponto de origem na formulação de políticas públicas é o estabelecimento, pela sociedade, dos temas que devam ser considerados públicos para que se tornem ações do Estado. São essas demandas da sociedade que geram ações do Estado para que se tornem políticas públicas, de modo que por meio da formulação e da aplicação de políticas públicas o Estado se torne mais concreto para o cidadão.

Tornadas ações do Estado, as políticas públicas visam à efetivação de direitos. Esse processo, vale afirmar, não é um jogo de anjos, mas um campo de disputas de posições, de valores, de compreensões diversas sobre o papel do Estado e, sobretudo, de decisões sobre a aplicação de recursos públicos. A definição de quais ações do Estado devam ser políticas públicas é tomada num ambiente em que diferentes grupos disputam seus interesses. Nesse ambiente de disputas, é esse jogo de forças que delimita o contorno em que a política pública é definida. Decidida a necessidade e a pertinência de que o Estado adote uma política pública, é necessário que sejam estabelecidas metas e estratégias para sua implementação, quando sempre haverá, em virtude da limitação de recursos, escolha de prioridades.

Nesse cenário de disputa de interesses, evidencia-se a importância da mobilização de grupos organizados da sociedade em face daquilo que é considerado importante, útil ou vantajoso moral, social ou materialmente a esses grupos. Afinal, as demandas desses grupos devem ser apresentadas de maneira orgânica a fim de que obtenham êxito em sua luta por direitos.

Os conflitos eventualmente gerados pelas diferentes posições em relação à diversidade das demandas, se democraticamente solucionados, terão como referência o interesse público. No entanto, vivemos num país de forte tradição patrimonialista, em que a esfera pública e a esfera privada e doméstica se misturam, sem as necessárias distinções entre os limites de cada uma. Não é preciso ser um investigador atento para compreender que as políticas públicas adotadas pelo Estado brasileiro nem sempre estiveram a serviço da resolução de problemas públicos, de interesse da maioria da população.

Muitos já estudaram os efeitos gerados pelo Estado patrimonialista, desde Weber com seus clássicos estudos (WEBER, 1991 e 1999) até a aplicação de seus conceitos sociológicos à realidade brasileira (FAORO, 1995 e 1997; SCHWARTZMAN, 1988). De maneira particular, Raimundo Faoro identificou o surgimento de estamentos burocráticos que se apossam do Estado para satisfação de seus próprios interesses. Por isso, o que o Estado escolhe fazer ou deixar de fazer nem sempre tem como critério o interesse público e o bem comum. 
O que a democracia nos diz sobre esse ambiente de conflito de interesses? O ambiente democrático é o mais eficiente para que a resolução de conflitos de interesse seja alcançada. É a forma de organização social e política que mais favorece a garantia de direitos da maioria e o respeito aos direitos das minorias. Mas também é forçoso admitir que a história política de nosso país não tem a democracia como seu marco definitivo. Os períodos democráticos experimentados na vida política brasileira caracterizam-se mais pela predominância de períodos de arbítrio e autoritarismo entremeados por períodos de soluços democráticos.

Nesse quadro geral é que se pode perguntar como a Educação e os Direitos Humanos tornaram-se políticas públicas no Brasil e como elas têm se comportado.

\section{A educação como política pública}

Nem sempre a educação foi considerada uma questão nacional. Não é escopo desse trabalho realizar um levantamento exaustivo sobre a maneira como o ensino se desenvolveu no país desde o período da colonização. Basta, no entanto, afirmar que a Matriz portuguesa não cuidou de instalar no país, pelas próprias mãos, um sistema de acesso ao ensino, optando por entregar essa missão à Congregação Jesuítica que a exerceu na forma de monopólio por 210 anos (1549 a 1759). Passado o período colonial e após o período imperial, com a proclamação da República, a dinâmica como se desenvolveu no Brasil o direito de acesso à educação evidencia que a República não republicanizou a educação, permanecendo esse direito de cidadania restrito à pequeníssima parcela da sociedade, diferente de países em que repúblicas se estabeleceram, especialmente na Europa, sob o manto dos ideais liberais insuflados pela Revolução Francesa.

No Brasil, foi a ampliação da classe média e do operariado urbano que impulsionou a luta pela educação de massas. A criação, em 1924, da Associação Brasileira de Educação, de perfil elitista, congregou profissionais da educação e propôs políticas educacionais para o setor mobilizando a sociedade por meio de Conferências e Congressos Nacionais. Aqui se encontra a origem no Movimento Renovador da Educação que culminou com a divulgação, em 1932, do Manifesto dos Pioneiros da Educação Nova. Destacam-se, nesse documento, a institucionalização da educação pública como direito cidadão de acesso ao ensino para ambos os sexos e dever do Estado, bem como da sua laicidade e gratuidade.

Outros aspectos foram também relevantes para que a educação fosse assumida como política pública. Dentre eles, é possível citar a criação do Ministério da Educação e Saúde e do Conselho Nacional de Educação (1930); as diversas diretrizes nacionais dos períodos que, hoje, são consideradas etapas 
da Educação Básica; e, além das Leis Orgânicas do Ensino, a Disposição - incluída na Constituição de 1934 - de que a União é responsável pela coordenação e execução da política nacional de educação. Destacam-se, sobremaneira, os enormes avanços consignados na Constituição de 1988, a começar pela consideração da educação como direito subjetivo, a ampliação da obrigatoriedade do Estado na oferta do ensino dos 4 aos 17 anos por meio de Emenda Constitucional de 2009 e, finalmente, os Planos Nacionais de Educação (2001-1011 e 2014-2024).

Os Planos Nacionais de Educação, aprovados como Leis federais pelo Congresso Nacional, ao estabelecerem metas e estratégias para ampliação e consolidação dos direitos à educação materializam-se como instrumentos por excelência de política pública educacional. Importante registrar que o PNE 2014-2024 teve como importante referência as conclusões da Conferência Brasileira de Educação (CONAE) realizada em 2010, cuja temática central se intitulou "Construindo o Sistema Nacional Articulado de Educação: o Plano Nacional de Educação, Diretrizes e Estratégias de Ação". Essa conferência nacional, dentre as dezenas de outras que se realizaram no país sobre diversas temáticas, constitui-se em espaço democrático de construção de acordos sobre os mais diferentes aspectos de natureza cultural, política, econômica, materializando a questão anteriormente citada da elaboração das políticas públicas como campo de disputa.

\section{Direitos humanos como política pública}

Deve-se considerar, preliminarmente, que todas as ações do Estado, compreendidas como instrumentos de alcance do bem-estar público, são, por óbvio, a qualquer tempo, ações de garantia de direitos humanos, em vista da dignidade de cada pessoa e dos coletivos nos quais está inserida.

No Brasil, o tema dos direitos humanos tem íntima relação com o período ditatorial iniciado em 1964. A tensão entre o papel do Estado e da sociedade civil, no contexto do regime militar instalado no país pelo golpe civil-militar de 1964, nos permite compreender as mobilizações sociais, quando indivíduos e grupos organizados voltaram-se contra os arbítrios do regime de maneira que esse foi um tema tornado público.

A luta pelos direitos humanos no Brasil está ligada à luta contra o arbítrio e pela redemocratização do país. As comissões de justiça e paz ligadas à Igreja católica, por exemplo, denunciaram torturas e assassinatos, exercendo um papel preponderante a comissão instalada na Arquidiocese de São Paulo, sob a condução de Dom Paulo Evaristo Arns. O processo de resistência democrática influenciou fortemente o estabelecimento dos direitos humanos como uma questão nacional. Viola (2008), no livro "Direitos humanos e demo- 
cracia no Brasil", faz uma extensa descrição e análise do papel dos movimentos sociais na defesa dos direitos humanos e de suas lutas.

É lícito, portanto, considerar que os direitos humanos como política pública são o resultado dessa luta que desaguou na promulgação da Constituição Federal de 1988. A Constituição cidadã, como ficou conhecida, reconheceu e positivou os anseios dos movimentos em defesa da dignidade humana. Especialmente na redação dos artigos $3^{\circ}$ e $5^{\circ}$.

O artigo $3^{\circ}$ elenca os objetivos fundamentais da República:"I - construir uma sociedade livre, justa e solidária; II - garantir o desenvolvimento nacional; III - erradicar a pobreza e a marginalização e reduzir as desigualdades sociais e regionais; IV - promover o bem de todos, sem preconceitos de origem, raça, sexo, cor, idade e quaisquer outras formas de discriminação" (BRASIL, 1998)

O artigo 5०, ao listar seus 78 incisos, várias alíneas e parágrafos, transfere para a Carta Magna como direitos fundamentais instituídos como cláusulas pétreas as afirmações da Declaração Universal dos Direitos Humanos (DUDH) e dos diversos outros instrumentos jurídicos internacionais que a completaram.

Além desse alicerce jurídico, algumas iniciativas institucionais podem ser apontadas como mecanismos importantes para a elevação dos direitos humanos à condição de política pública. Dentre elas, é importante assinalar a criação de uma estrutura orgânica de governo com a incumbência de elaborar e executar políticas públicas para essa área. Inicialmente na forma de Secretaria Nacional ligada ao Ministério da Justiça e, depois, como Secretaria Especial vinculada diretamente à Presidência da República, o que lhe emprestava uma função articuladora de outros ministérios para o alcance dos objetivos gerais de governo no campo dos direitos humanos. E, por fim, instituído como ministério agregando áreas como direitos das mulheres, igualdade racial, dentre outras políticas focais.

Pode ser, ainda, apontada como iniciativa institucional a elaboração de três programas nacionais de direitos humanos. Em 1996, o primeiro programa nacional centrou-se na garantia dos direitos civis e políticos. Em 2002 e 2009 esse programa foi atualizado sendo incorporados temas que contemplaram os direitos econômicos, sociais e culturais, provenientes de demandas de movimentos sociais emergentes. O Programa Nacional de Direitos Humanos III, aprovado pelo Decreto Presidencial no 7.037, de 21/12/2009, deu-se como resultado de discussões intersetoriais que se estabeleceram a partir de inúmeras conferências municipais, estaduais, regionais e, por fim, pelas conclusões da 11a Conferência Nacional de Direitos Humanos, em dezembro de 2008, na celebração dos sessenta anos da DUDH. Estruturado em seis eixos orientadores e vinte e cinco diretrizes, foi o programa que mais avançou como um instrumento de Estado para orientar as políticas públicas de direitos humanos. 


\section{A educação em direitos humanos como política pública}

A EDH como política pública, favoreceu-se do movimento já ocorrido de assunção dos direitos humanos a essa mesmacondição, considerando a Constituição de 1988 e os Programas Nacionais de Direitos Humanos aqui referidos, especialmente na sua terceira versão de 2009, que incluiu como um de seus eixos temáticos a "Educação e Cultura em Direitos Humanos".

Pode-se afirmar que o tema da EDH já estava presente na DUDH quando, em seu preâmbulo, chama atenção para a necessidade de que os direitos humanos ali proclamados sejam objeto de ensino e educação por parte dos indivíduos e das instituições, uma indicação de que a consciência do outro como um igual precisa ser afirmada.

A presente Declaração Universal dos Direitos Humanos, como o ideal comum a ser atingido por todos os povos e todas as nações, com o objetivo de que cada indivíduo e cada órgão da sociedade, tendo sempre em mente esta Declaração, se esforce, através do ensino e da educação, por promover o respeito a esses direitos e liberdades (ONU, 2013)

Em 1993, a realização da Conferência de Viena realizada pela ONU colocou foco no chamamento desse preâmbulo promovendo a década da Educação em Direitos Humanos e convocando os Estados-membros a organizarem processos educativos e programas nacionais para definir diretrizes, finalidades e práticas relativas a essa temática. A criação de uma estrutura orgânica no interior da Secretaria Especial de Direitos Humanos, responsável pela condução de ações específicas para essa área, a Coordenação Geral de Educação em Direitos Humanos, bem como a constituição do Comitê Nacional de Educação em Direitos Humanos, em 2003, foram fundamentais para que o Brasil avançasse na adoção da Educação em Direitos Humanos como política pública.

O Comitê Nacional de Educação em Direitos Humanos foi responsável pela elaboração do Plano Nacional de Educação em Direitos Humanos (PNEDH), em sua primeira versão, de 2003, levada a uma discussão nacional com inúmeras contribuições que redundaram na redação definitiva e em vigor, de 2006. O PNEDH, em acordo com o Programa Mundial de Educação em Direitos Humanos da Unesco, dispõe sobre princípios e finalidades da EDH como ação multidimensional que orienta a formação de sujeitos de direitos. Compreendida como política pública, a EDH - atravessada por valores, relações, práticas sociais e institucionais - articula diferentes dimensões e utiliza linguagens e recursos metodológicos e materiais de apoio. O PNEDH está estruturado em cinco áreas temáticas: a educação básica, a educação superior, a educação não formal, a educação dos profissionais dos sistemas de justiça e segurança e a educação na mídia.

Além do plano nacional, que orienta as políticas públicas nessa área, 
e considerando a relevância e a amplitude dos temas educação básica e educação superior, é importante destacar a elaboração das Diretrizes Gerais de Educação em Direitos Humanos aprovadas pelo Conselho Nacional de Educação, em 2012. Essas diretrizes vieram como resposta a ações programáticas descritas no PNDH III, de estabelecer diretrizes curriculares para a Educação Básica e dos cursos de graduação (Diretriz 19, Objetivos Estratégicos I e II) e são o resultado das contribuições de inúmeras entidades, movimentos e personalidades reconhecidas na área. Essas diretrizes fixaram parâmetros para a educação formal em todos os níveis e modalidades do ensino.

Importante ressaltar que o Conselho Nacional de Educação já vinha se manifestando a respeito da relação entre a educação e os direitos humanos por meio de atos normativos anteriores como as Diretrizes Gerais para a Educação Básica, as Diretrizes Curriculares Nacionais para a Educação Infantil, para o Ensino Fundamental de nove anos e para o Ensino Médio, bem como em normativas específicas para modalidades da educação como a Educação de Jovens e Adultos, a Educação para Jovens em Situação de Privação de Liberdade nos Estabelecimentos Penais, a Educação Especial, dentre outras.

Ao fixar as Diretrizes Gerais de Educação em Direitos Humanos, o ConseIho Nacional de Educação considerou a que a inserção de conhecimentos concernentes a essa temática nos currículos pode se dar de acordo com a decisão autônoma dos sistemas e das instituições de ensino, quer pela transversalidade, que pela adoção de conteúdos específicos de uma disciplina, ou mesmo combinando a transversalidade e a disciplinaridade. Dessa maneira, é fundamental compreender que a transversalidade na educação em direitos humanos ultrapassa os espaços da sala de aula, alcançando todo o ambiente escolar, de modo que seus princípios e objetivos estejam presentes nos projetos político pedagógicos, nos regimentos escolares, nos materiais didáticos, na gestão democrática.

As iniciativas nacionais aqui apontadas, tanto de criação de estruturas, comitês, planos e diretrizes, repercutiram em várias Unidades da Federação que, igualmente, criaram suas estruturas e documentos orientadores, considerando suas peculiaridades regionais. Dessa maneira, é possível considerar que os marcos regulatórios da EDH como política pública são bastante avançados. Pode-se afirmar que a EDH, em termos de estrutura normativa, tem potencial para cumprir seus objetivos e ser um importante mecanismo de aprofundamento, radicalização e fortalecimento da democracia e do Estado de Direito.

\section{A conjuntura brasileira e os desafios da EDH}

Considerando o cenário constitucional, legal e normativo aqui referido em relação à Educação, aos Direitos Humanos e à Educação em Direitos 
Humanos, não é possível desconsiderar a influência que conjuntura nacional vem exercendo nas políticas públicas dessas três áreas. Não é objeto desse artigo produzir uma análise da conjuntura brasileira. Basta, aqui, lembrar que, no período da redemocratização do país, especialmente durante a vigência da Constituição Federal de 1988, o Brasil viveu a experiência da eleição de sete presidentes da República e a realização de quinze eleições sob o manto dos princípios consignados na Carta Magna. Desde o governo José Sarney (19851990) o tema dos direitos humanos fez-se presente ao anunciar, em discurso na ONU, a intenção de adesão do Brasil aos Pactos de Direitos Civis e Políticos e às Convenções contra a Tortura e sobre os Direitos Econômicos, Sociais e Culturais, instrumentos que seriam objeto de decretos no governo seguinte, de Collor de Mello (1990-1992). Como já visto, considerando a natureza dos direitos humanos como política pública, o governo Fernando Henrique Cardoso (1995-2003), de maneira mais objetiva, criou a Secretaria Nacional de Direitos Humanos no Ministério da Justiça, depois transformada em Secretaria de Estado de Direitos Humanos com status de Ministério e promoveu a edição de dois programas nacionais. Na sequência, o governo Lula da Silva (2003-2011) alterou a natureza administrativa da Secretaria criada por FHC, dando-lhe o status de Secretaria Especial ligada à Presidência da República e decretou, como resultado de ampla participação da sociedade civil, o Programa Nacional de Direitos Humanos III. No governo de Dilma Roussef (2011-2016), foi criado o Ministério da Mulher, da Igualdade Racial e dos Direitos Humanos, como fusão de três Secretarias Especiais. O governo Michel Temer (2016-2019) extinguiu esse ministério assim que assumiu interinamente o governo com o afastamento de Dilma Roussef, recriando-o a seguir com o nome de Ministério dos Direitos Humanos. Com a eleição de Jair Messias Bolsonaro (2019-atual), essa estrutura passou a denominar-se Ministério da Mulher, da Família e dos Direitos Humanos.

O impeachment da presidenta Dilma marcou a passagem para um período de importantes retrocessos políticos, econômicos e sociais, refletindo decisivamente na área dos direitos humanos. O Relatório da Anistia Internacional de 2016/2017 fez pesadas avaliações negativas que envolviam uso excessivo da força policial, limitações de gastos públicos durante vinte anos por meio de emenda constitucional, execuções e desaparecimentos forçados, violência contra mulheres, violações aos direitos das crianças, ataques a defensores de direitos humanos dentre outras (ANISTIA INTERNACIONAL, $\mathrm{s} / \mathrm{d}$ ). Após décadas de queda nos índices de mortalidade infantil, registrou-se aumento de mortes de crianças e o país voltou a frequentar o mapa da fome registrado pelo Índice Global da Fome, caindo 13 posições no ranking de 119 países (ÍNDICE GLOBAL DA FOME, 2020). Os assassinatos de pessoas da população LGBT elevaram-se em 30\% nos anos de 2016/2017, tendo o portal 
eletrônico do Senado Federal registrado que o Brasil é o país onde mais se assassinam homossexuais no mundo (BORTONI, 2018).

As eleições de 2018, ao sufragarem como eleito o candidato Jair Messias Bolsonaro, já anunciavam que os retrocessos verificados no período de governo Temer seriam aprofundados. Durante o período de campanha, o candidato vencedor não poupou críticas aos direitos humanos e seus defensores. Usando os velhos jargões "bandido bom é bandido morto" ou "direitos humanos para humanos direitos" já anunciava que, sob sua presidência, haveria uma classe de seres humanos considerados sujeitos de direitos e outra descartável. Inúmeras manifestações públicas foram feitas de maneira depreciativa contra mulheres, negros a população LGBTQI+. No programa de governo inscrito no Tribunal Superior Eleitoral (BRASIL ACIMA DE TUDO, DEUS ACIMA DE TODOS, 2018), a expressão direitos humanos é registrada apenas uma vez nas proposições sobre segurança pública, anunciando redirecionamento do tema para priorizar as vítimas da violência, a revisão do Estatuto do Desarmamento, da redução da maioridade penal e da garantia do "excludente de ilicitude", instituto por meio do qual policiais podem matar suspeitos sem serem punidos pela justiça ao recorrerem a esse dispositivo. Medidas, como se pode observar, inteiramente em confronto com a concepção contemporânea de direitos humanos.

Já no período de governo, o tratamento dado aos direitos humanos é possível constatar tantos retrocessos que o relatório da Anistia Internacional chega a apontar que a situação instalada é de tal maneira grave que se compara período anterior à Constituição Federal de 1988, podendo-se inferir que os direitos fundamentais foram proscritos pelas ações de governo. Na sequência, o Informe Anual 2020/2021 da mesma entidade mostra que houve aprofundamento de violações e os riscos de retrocesso em relação aos direitos conquistados aprofundou-se, contexto em que a mobilização por direitos assume um papel fundamental (ANISITIA INTERNACIONAL, 2021).

É nessa conjuntura que a Educação em Direitos Humanos assume um papel primordial como ação capaz de promover o enfrentamento de preconceitos e violações de direitos, constituindo-se fundamental instrumento para a construção de uma nova mentalidade, especialmente voltada para as gerações em processo de formação. Ainda assim, é forçoso reconhecer que os processos educativos formais pela via da escolarização estão igualmente atingidos por ações governamentais que reverberam os movimentos conservadores com acusações e perseguições a professores e instituições educativas sob o falacioso argumento de doutrinação ideológica. A verdadeira cruzada que se instalou no país contra a chamada "ideologia de gênero", os movimentos em torno do tema da "escola sem partido", as referências depreciativas sobre as universidades, inclusive e principalmente aquelas vinculadas adminis- 
trativamente ao próprio governo federal e, até mesmo, ataques infundados e desqualificados ao patrono da educação brasileira Paulo Freire, sem nenhuma base de realidade, são elementos que evidenciam o quadro desfavorável para uma consequente materialização da política pública de educação em direitos humanos. Avanços conquistados ao longo de anos e positivados no arcabouço jurídico e normativo nacional são sistematicamente desconsiderados ou desqualificados sob alegação de se constituírem pura ideologia. Essas posturas confrontam-se radicalmente com as políticas contemporâneas de direitos humanos. A pandemia do Covid-19 recrudesceu esse panorama governamental em função da postura negacionista e contrária à Ciência, tendo a União desertado de sua competência de liderar e coordenar os processos de enfrentamento ao vírus que permanece ceifando a vida de brasileiros.

Ainda assim, é preciso considerar que os avanços já conquistados são fruto de luta de setores organizados da sociedade. As gerações que nos precederam contabilizam mortos, desaparecidos, exilados, atingidos em sua liberdade para que esses direitos fossem reconhecidos e garantidos. A defesa dos direitos conquistados é um dever de lealdade aos que nos antecederam. Mais do que nunca, a EDH deve ser tomada como um instrumento básico para enfrentar preconceitos, violações de direitos e propiciar uma nova e renovada mentalidade sobre a importância da promoção e da garantia dos direitos humanos, atuando na consciência dos indivíduos para que sintam como se fosse em si qualquer violação dos direitos humanos.

O nosso reconhecimento como sujeitos de direitos está submetido à fragilidade dos mecanismos reais da democracia. Na conjuntura em que vivemos, ela está em risco e é preciso assumir que a existência de uma sociedade democrática depende, também, da preparação dos indivíduos para sua vivência. Educa-se para a cidadania, para a democracia e para o respeito aos direitos humanos. Esse é o papel da EDH, como lembrado no preâmbulo da DUDH.

A garantia de direitos é um dos fundamentos do estado democrático de direitos. Quando apenas uma parcela da população tem assegurados seus direitos, não se pode afirmar que haja cidadania plena e, portanto, a democracia não é efetivada. O papel da EDH, nesse contexto é, portanto, atuar dentro de suas finalidades para o fortalecimento da democracia e do estado democrático de direito.

A ideia amplamente divulgada de que os avanços democráticos alcançados no país e consubstanciados na Constituição Federal de 1988 são uma conquista irreversível é comparável à ideia igualmente disseminada de que os direitos humanos emplacaram definitivamente na sociedade brasileira. Ambas as ideias, de que estão consolidadas a democracia e os direitos humanos no país, não se sustentam na realidade fática. E revelam o desconhecimento do ensinamento deixado por Norberto Bobbio de que os direitos humanos 
têm uma natureza histórica, alertando para a necessidade de que a sociedade esteja sempre de prontidão para manter os direitos conquistados, na perspectiva de ampliação dessa conquista.

A natureza histórica dos direitos humanos empresta ainda mais força à chamada para sua promoção por meio do ensino e da educação, tendo em vista que é forçoso reconhecer que, passados mais de setenta anos da DUDH e mais de trinta da promulgação da Constituição em vigor, as violações de direitos humanos permanecem sendo um desafio a enfrentar. Norberto Bobbio nos lembraa importância da natureza histórica dos direitos humanos.

\begin{abstract}
Do ponto de vista teórico, sempre defendi - e continuo a defender, fortalecido por novos argumentos - que os direitos do homem, por mais fundamentais que sejam, são direitos históricos, ou seja, nascidos em certas circunstâncias, caracterizados por lutas em defesa de novas liberdades contra velhos poderes, e nascidos de modo gradual, não todos de uma vez e nem de uma vez por todas (BOBBIO, 1998, p. 5)
\end{abstract}

É preciso, portanto, estarmos todos atentos, vigilantes, alertas para os enfrentamentos que forem necessários para que nada possa impedir os avanços no processo civilizatório, este sim irreversível, mas sempre com a compreensão de que os direitos humanos não nascem todos de uma vez $\mathrm{e}$ nem de uma vez por todas.

É nessa perspectiva que a reativação da Rede Nacional de Educação em Direitos Humanos constitui-se passo decisivo par essa conquista. Fundada em 1995, tendo como coordenadora a socióloga Margarida Genevois, participante ativa da Comissão de Justiça e Paz da Arquidiocese de São Paulo, sua finalidade foi agregar entidades que vinham desenvolvendo experiências nesse campo. Visava a refletir sobre concepções e significados de uma educação para a cidadania, para a democracia e para os direitos humanos. A Rede influenciou fortemente a criação do Comitê Nacional de Educação em Direitos Humanos da então Secretaria Nacional de Direitos Humanos da Presidência da República, tendo vários de seus integrantes participado do referido comitê e elaborado a versão original do Plano Nacional de Educação em Direitos Humanos. A Rede foi desativada no final dos anos 2000, momento em que ocorreu a expansão de políticas públicas de EDH assumidas pelo Estado brasileiro. A conjuntura desfavorável à EDH aqui já relatada induziu a reaglutinação de forças em favor da EDH, tendo sido a Rede reativada em um Encontro Nacional ocorrido em dezembro de 2020. Diante do quadro conjuntural por que passa o país, a Rede, tomando como diretriz de suas ações, políticas e iniciativas o Plano Nacional de Educação em Direitos Humanos, pretende contribuir para o fortalecimento da democracia por meio da promoção da EDH tendo em vista a formação para a cidadania, para o respeito integral aos 
direitos humanos, para a defesa da justiça social e ambiental. Para isso postula a realização de práticas de educação emancipadora, crítica, problematizadora, inclusiva, intercultural e democrática.

Nesse cenário geral, é certo que há muito o que celebrar e, também, muito o que lamentar porque os direitos humanos são sempre uma obra inacabada e que não há luta pelos direitos humanos sem conflitos, razão por que defender os direitos humanos é estar na resistência e na contra hegemonia. Para essa quadra de profundas contradições são todos chamados. Educar em direitos humanos é um imperativo para a construção de uma sociedade livre, igualitária, justa e fraterna, onde as diferenças sejam consideradas e valorizadas porque parte da riqueza humana, e onde o reconhecimento do outro como um diferente e um semelhante permite que todos e todas se olhem na mesma altura do olhar.

\section{Referências}

ANISTIA INTERNACIONAL. Informes anuais. Disponível em: https://anistia.org. br/informe-se/informes-anuais/. Acesso em: 5 mai. 2021.

BOBBIO, Norberto. A era dos direitos. Rio de Janeiro: Campus, 1988.

BORTONI, Larissa. Brasil é o país onde mais se assassinam homossexuais no mundo. Rádio Senado / Portal do Senado Federal. Brasília: mai. 2018. Disponível em: https://www12.senado.leg.br/radio/1/noticia/2018/05/16/brasil-e-opais-que-mais-mata-homossexuais-no-mundo. Acesso em: 5 mai. 2021.

BRASIL. Constituição da República Federativa do Brasil de 1988. Brasília: Presidência da República / Casa Civil / Subchefia para Assuntos Jurídicos. 1988. Disponível em: http://www.planalto.gov.br/ccivil_03/Constituicao/ Constituicao.htm. Acesso em 5 mai. 2021.

BRASIL. Programa nacional de direitos humanos - 3. Brasília, DF: Secretaria de Direitos Humanos da Presidência da República, 2010a.

BRASIL. Ministério da Educação. Documento final da CONAE. Brasília, DF: MEC, 2010b.

BRASIL.Ministério da Educação. Parecer CNE/CP no 8, de 6 de março de 2012. Diretrizes Nacionais para a Educação em Direitos Humanos. Diário Oficial da União, Brasília, DF, 2012a. 
BRASIL. Ministério da Educação. Resolução CNE/CP no 1, de 30 de maio de 2012. Estabelece Diretrizes Nacionais para a Educação em Direitos Humanos. Diário Oficial da União, Brasília, DF, 2012b.

BRASIL. Plano Nacional de Educação em Direitos Humanos. Ministério dos Direitos Humanos. Brasília: 2018. Disponível em: https://www.gov.br/mdh/pt$\mathrm{br} /$ navegue-por-temas/educacao-em-direitos-humanos/DIAGRMAOPNEDH. pdf. Acesso em: 5 mai. 2021.

BRASIL ACIMA DE TUDO. DEUS ACIMA DE TODOS. Proposta de Plano de Governo. Jair Bolsonaro. Disponível em: https://divulgacandcontas.tse. jus.br/candidaturas/oficial/2018/BR/BR/2022802018/280000614517/ proposta_1534284632231.pdf. Acesso em: 5 mai. 2021.

FAORO, Raymundo. Os donos do poder: formação do patronato político brasileiro. São Paulo: Ed. Globo, v. I, 1997; v. II, 1995.

ÍNDICE GLOBAL DA FOME. Disponível em: https://www.globalhungerindex. org/pdf/pt/2020.pdf. Acesso em: 5 mai. 2021.

SWARTZMAN, Simon. Bases do autoritarismo brasileiro. Rio de Janeiro: Editora Fundação Getúlio Vargas, 1986.

UNITED NATION / HUMAN RIGTHS / OFFICE OF THE HIRH COMISSIONER. Declaração Universal dos Direitos Humanos. Disponível em: https://www.ohchr. org/EN/UDHR/Pages/Language.aspx?LangID=por. Acesso em: 5 mai. 2021.

VIOLA, Solon Eduardo Annes. Direitos humanos e democracia no Brasil. São Leopoldo: Unisinos, 2008.

WEBER, Max. Economia e sociedade: fundamentos de uma sociologia compreensiva. Brasília: Editora UnB, v. I, 1991; v. II, 1999. 
